\title{
Effect of cataract extraction and posterior chamber lens implantation on outflow facility and its response to pilocarpine in Korean subjects
}

\author{
Changwon Kee, Seong-Heon Moon
}

\begin{abstract}
Aim-To investigate the effect of the lens on outflow facility in Korean patients with cataracts.

Methods-Intraocular pressure was measured by Goldmann applanation tonometry in 42 patients with cataracts and outflow facility was determined by tonography preoperatively, before and after instillation of pilocarpine. All patients received clear corneal phacoemulsification and silicone foldable intraocular lens implantation within the capsular bag by one surgeon. Two months after surgery, slit lamp examination and gonioscopy were performed and intraocular pressure and outflow facility were again determined. Statistical analysis was carried out using the Student's paired $t$ test.

Results-There were no anterior chamber reactions and no visible trabecular meshwork damage 2 months after surgery. Intraocular pressure 2 months after lens extraction decreased by a mean of 2.4 (SE $0.4) \mathrm{mm} \mathrm{Hg}(\mathrm{p}<0.001)$ compared with the preoperative value; postoperative outflow facility with and without pilocarpine increased by $0.080(0.019) \mu 1 / \mathrm{min} / \mathrm{mm} \mathrm{Hg}$ $(\mathrm{p}<0.001)$ and $0.045(0.014) \mu 1 / \mathrm{min} / \mathrm{mm} \mathrm{Hg}$ $(p<0.001)$, respectively, at 2 months compared with preoperative values. The facility response to pilocarpine after lens extraction, relative to the baseline value and preoperative response, increased by $10.7(7.1) \%$ which was not statistically significant $(p>0.1)$.

Conclusion-Lens extraction causes a reduction in intraocular pressure and an increase in outflow facility in Korean subjects. Pilocarpine causes an increase in outflow facility which persists after cataract extraction and posterior chamber lens implantation.

(Br F Ophthalmol 2000;84:987-989)
\end{abstract}

Department of Ophthalmology, Samsung Medical Center College of Medicine,

Sungkyunkwan

University, Seoul

135-710, Korea

C Kee

S-H Moon

Correspondence to: Dr C Kee

cwkee@ophthalmology.org

Accepted 25 April 2000 and mechanical posterior depression of the lens, ${ }^{6}$ the latter presumably by increasing ten-

Anterior tendons of the ciliary muscle attach to the scieral spur, Schwalbe's line, and cribriflow pathway that increase outflow facility increased by voluntary accommodation, ${ }^{3}$ electrical stimulation of the oculomotor nerve, ${ }^{4}$ parasympathetic drugs such as pilocarpine, ${ }^{5}$ sion of the zonules and ciliary body on the meshwork and Schlemm's canal. If the lens affects ciliary muscle contractility via zonular tension, the outflow facility response to pilocarpine may be changed after lens extraction. We investigated the effect of the lens on ciliary muscle contractility by measuring the tonographic outflow facility before and after $2 \%$ pilocarpine instillation, before and after cataract surgery.

Subjects and methods

Clear cornea phacoemulsification ${ }^{8}$ and posterior chamber foldable silicone intraocular lens (AMO Phacoflex II, Allergan Medical Optics, Irvine, CA, USA) implantation in the bag were performed in one eye of 42 Korean patients (19 men, 23 women) at the Department of Ophthalmology, Samsung Medical Center. Their mean age was 63.5 (SD 12.3) years (range 27-82).

All patients entering the study received preoperative counselling with regard to participation in the study. Participation was voluntary and patients gave written informed consent. The study followed the principles of the Declaration of Helsinki.

Patients with a history of previous ocular disease, family history of glaucoma, use of antiglaucoma drugs, and previous intraocular surgery were excluded.

All cataract operations were performed by one surgeon (CK). A $3 \mathrm{~mm}$ chord length clear corneal incision was made just inside the limbus. A $2 \mathrm{~mm}$ corneal tunnel was created and the anterior chamber was entered using a $3 \mathrm{~mm}$ diamond keratome. Continuous curvilinear capsulorhexis, hydrodissection, and hydrodelineation of the cataractous lens were performed after intracameral injection of a viscoelastic agent (Healon, Pharmacia \& Upjohn, Sweden). Phacoemulsification was used to remove the lens nucleus and irrigation and aspiration were used to remove residual cortical material. A foldable silicone posterior chamber intraocular lens was then placed within the capsular bag. The viscoelastic agent was aspirated from the anterior chamber and the wounds were evaluated for leakage; all were watertight at the end of surgery. $0.5 \mathrm{ml}$ gentamicin $(40 \mathrm{mg} / \mathrm{ml})$ was injected subconjunctivally. Electrocautery or sutures were not used during surgery. Posterior capsular rupture or any other complications did not occur intraoperatively.

Fluorometholone, ofloxacine (both Santen, Osaka, Japan), and tobramycin (Daewoong, 
Table 1 Intraocular pressure and outflow facility changes

\begin{tabular}{|c|c|c|c|c|c|}
\hline & Preop & Postop & Postop-preop & Postop/preop & $p$ Value \\
\hline IOPop (mm Hg) & 15.3 & $(0.4)$ & $-2.4 \quad(0.4)$ & $0.85(0.02)$ & $<0.001$ \\
\hline IOPcon $(\mathrm{mm} \mathrm{Hg})$ & $15.4 \quad(0.4)$ & $15.0 \quad(0.3)$ & $-0.4 \quad(0.3)$ & $0.98(0.02)$ & $>0.1$ \\
\hline $\mathrm{Cbl}(\mu \mathrm{l} / \mathrm{min} / \mathrm{mm} \mathrm{Hg})$ & $0.260(0.011)$ & $0.305(0.015)$ & $0.045(0.014)$ & $1.23(0.06)$ & $<0.001$ \\
\hline Cpilo $(\mu \mathrm{l} / \mathrm{min} / \mathrm{mm} \mathrm{Hg})$ & $0.330(0.013)$ & $0.410(0.022)$ & $0.080(0.019)$ & $1.26(0.06)$ & $<0.001$ \\
\hline
\end{tabular}

Data are mean (SE), ratios have no units.

IOPop = intraocular pressure of operated eye; IOPcon = intraocular pressure of contralateral non-operated eye; Cbl = outflow facility without pilocarpine; Cpilo = outflow facility with pilocarpine; preop = preoperative; postop = postoperative.

Seoul, Korea) eye drops were given to all patients three times daily for 1 month postoperatively.

Intraocular pressure was measured using a Goldmann applanation tonometer before surgery. Outflow facility was measured under topical anaesthesia with a pneumatonometer (Mentor 30 Classic, Norwell, MA, USA) before and 1 hour after instillation of $2 \%$ pilocarpine $\mathrm{HCl}$ (Samil, Seoul, Korea). Two months after surgery the intraocular pressure and outflow facility were similarly determined in all patients.

The effect of lens extraction on the facility response to pilocarpine was calculated from the formula:

(postCpilo/postCbl)/(preCpilo/preCbl) where preCpilo $=$ preoperative outflow facility with pilocarpine administration, preCbl = preoperative outflow facility without pilocarpine administration, postCpilo $=$ postoperative outflow facility with pilocarpine administration, and postCbl = postoperative outflow facility without pilocarpine administration.

Data are presented as mean (SE) values except age which is presented as mean (SD). Statistical analysis was carried out using the Student's two tailed paired $t$ test.

\section{Results}

Slit lamp examination and gonioscopy 2 months after surgery revealed no anterior chamber inflammatory reaction and no evidence of damage to the trabecular meshwork such as increased pigments in the trabecular meshwork, development of peripheral anterior synechia, or cyclodialysis. Intraocular pressure before and 2 months after lens extraction was $15.3(0.4) \mathrm{mm} \mathrm{Hg}$ and $12.9(0.4) \mathrm{mm} \mathrm{Hg}$, respectively, a decrease of $2.4(0.4) \mathrm{mm} \mathrm{Hg}$ $(\mathrm{p}<0.001)$ following surgery. In the contralateral non-operated eye the intraocular pressure before and 2 months after lens extraction was $15.4(0.4) \mathrm{mm} \mathrm{Hg}$ and $15.0 \quad(0.3) \mathrm{mm} \mathrm{Hg}$, respectively, a non-significant decrease of 0.4 (0.3) $\mathrm{mm} \mathrm{Hg}(p>0.1)$. Outflow facility without pilocarpine before and 2 months after lens extraction was $0.260(0.011) \mu \mathrm{l} / \mathrm{min} / \mathrm{mm} \mathrm{Hg}$ and $0.305(0.015) \mu \mathrm{l} / \mathrm{min} / \mathrm{mm} \mathrm{Hg}$, respectively, an increase of $0.045(0.014) \mu \mathrm{l} / \mathrm{min} /$ $\mathrm{mm} \mathrm{Hg}(\mathrm{p}<0.001)$ after surgery. With pilocarpine instillation the outflow facility before and 2 months after lens extraction was 0.330 (0.013) $\mu \mathrm{l} / \mathrm{min} / \mathrm{mm} \mathrm{Hg}$ and $0.410(0.022) \mu \mathrm{l} /$ $\mathrm{min} / \mathrm{mm} \mathrm{Hg}$, respectively, an increase of 0.080 $(0.019) \mu \mathrm{l} / \mathrm{min} / \mathrm{mm} \mathrm{Hg} \quad(\mathrm{p}<0.001) \quad$ following surgery (Table 1 ). The facility response to pilocarpine after lens extraction relative to the baseline and preoperative response increased by $10.7(7.1) \%$, which was not statistically significant $(p>0.1)$.

\section{Discussion}

The ciliary muscle plays a major part in the regulation of outflow facility. ${ }^{9}$ Contraction of ciliary muscle resulting from various stimulations leads to an increase in outflow facility. ${ }^{3-7}$ By measuring outflow facility tonographically before and after lens extraction, with and without pilocarpine, and analysing the changes, the effect of the lens on ciliary muscle contractility can be estimated indirectly. In addition, as an increase in outflow facility induces a decrease in intraocular pressure, the tonographic data may be corroborated by checking the intraocular pressure.

Previous reports on intraocular pressure changes after cataract extraction showed that the intraocular pressure increased in the immediate postoperative period, but was not significantly different from the preoperative value in the long term. ${ }^{10}{ }^{11}$ However, as the technique of cataract surgery has improved, more recent reports have indicated that the intraocular pressure decreased significantly by 2.0-3.3 $\mathrm{mm} \mathrm{Hg}$ after cataract extraction. ${ }^{12}{ }^{13}$ We used a clear cornea phacoemulsification technique which did not involve procedures that may affect the intraocular pressure such as a corneoscleral incision and sutures which may damage or distort the trabecular meshwork, and episcleral electrocautery and conjunctival peritomy which may damage the episcleral venous plexus. Our results also showed a significant reduction in intraocular pressure of $2.4 \mathrm{~mm} \mathrm{Hg} 2$ months after cataract extraction.

There are few reports on changes in outflow facility following cataract surgery. Lee and Trotter ${ }^{14}$ reported that the outflow facility was diminished in the early postoperative period and had returned to the preoperative value 12 weeks after extracapsular cataract extraction. Meyer $e t a l^{15}$ studied changes in the outflow facility after phacoemulsification and posterior chamber intraocular lens implantation through scleral tunnel incision and reported that the outflow facility was significantly increased one day after surgery $(0.240 \mu \mathrm{l} / \mathrm{min} / \mathrm{mm} \mathrm{Hg}$ versus $0.410 \mu 1 / \mathrm{min} / \mathrm{mm} \mathrm{Hg}$ ), but there were no significant changes in outflow facility 1 week, 6 weeks, and 1 year after surgery. However, our data showed a statistically significant increase in outflow facility 2 months after cataract extraction $\quad(0.260 \mu \mathrm{l} / \mathrm{min} / \mathrm{mm} \mathrm{Hg}$ versus $0.310 \mu \mathrm{l} / \mathrm{min} / \mathrm{mm} \mathrm{Hg}$ ). This discrepancy may reflect differences in surgical technique. Tennen and Masket ${ }^{16}$ reported that the intraocular 
pressure was significantly decreased by $1.9 \mathrm{~mm} \mathrm{Hg} 1$ year after clear corneal incision phacoemulsification compared with the preoperative value while there were no changes in intraocular pressure 1 year after scleral tunnel incision phacoemulsification.

It may be better to follow up for a longer period and to measure the outflow facility but, because of the advancement of modern techniques of cataract surgery, these days it is hard to observe any inflammatory reactions in the anterior chamber even 1 month after cataract surgery. The outflow facility measured 2 months after cataract surgery may not therefore be influenced by inflammatory changes, which may affect uveoscleral outflow.

The lens is connected to the ciliary muscle by zonules, and a constant tension exists among them. ${ }^{17}$ If the lens is removed the zonular tension is decreased. This reduction in zonular tension after cataract extraction might affect ciliary muscle mobility. Hence, with the same stimulation, outflow facility might increase more or less than before cataract surgery. Furthermore, the length of the foldable intraocular lens we used was $13.0 \mathrm{~mm}$ which is greater than the diameter of the crystalline lens. If the intraocular lens haptics push the lens capsule outwards, thereby decreasing further the tension of the zonules, the mobility of the ciliary muscle might be altered even more.

Croft et $a l^{18}$ reported that, following intracapsular lens extraction in rhesus monkeys, the ciliary muscle flattens against the sclera and the movements of the ciliary muscle in response to electrical stimulation of the midbrain are changed. They concluded that the function of the ciliary muscle is dependent on the integrity of the normal relation between the lens and ciliary muscle. However, in our patients the outflow facility response to pilocarpine did not change after lens removal. This suggests that, while neuronally stimulated ciliary muscle mobility may be affected by lenticular-ciliary muscle interaction, pharmacologically induced ciliary muscle mobility may not be changed by lens removal or the change may not alter the resulting facility relevant deformation of the trabecular meshwork.

Because most of our cataract patients were elderly we were not able to analyse changes in ciliary muscle contractility after cataract ex- traction as a function of age. Our data indicate that lens extraction decreases intraocular pressure and increases outflow facility. However, lenticular-ciliary muscle interaction via the zonule does not appear to influence the outflow facility response to pilocarpine.

The authors thank Dr Paul L Kaufman, Department of Ophthalmology and Visual Sciences, University of WisconsinMadison for reviewing the manuscript and Dr Seonwoo Kim for assisting with data analysis.

This study was supported by grant SMC98 from the Samsung Medical Center, Seoul, Korea.

1 Rohen JW, Lütjen-Drecoll E. Morphology of aqueous outflow pathways in normal and glaucomatous eyes. In: Ritch R, Shields MB, Krupin T, eds. The glaucomas. Vol 1. 2nd ed. St Louis: Mosby, 1996:89-123.

2 Kaufman PL, Bárány EH. Loss of acute pilocarpine effect on outflow facility following surgical disinsertion and retrodisplacement of the ciliary muscle from the scleral spur in the cynomolgus monkey. Invest Ophthalmol 1976;15:793-807.

3 Armaly MF, Jepson NC. Accommodation and the dynamics of the steady-state intraocular pressure. Invest Ophthalmol Vis Sci 1962;1:480-3.

4 Crawford K, Terasawa E, Kaufman PL. Reproducible stimulation of ciliary muscle contraction in the cynomolgus stimulation of ciliary muscle contraction in the cynomolgus monkey via a permanent in

5 Kaufman PL, Bárány EH. Loss of acute pilocarpine effect on outflow facility following surgical disinsertion and retrodisplacement of the ciliary muscle from the scleral spur in the cynomolgus monkey. Invest Ophthalmol 1976;15:793-807.

6 Van Buskirk EM. Changes in the facility of aqueous outflow induced by lens depression and intraocular pressure in excised human eyes. Am F Ophthalmol 1976;82:736-40.

7 Van Buskirk EM, Grant WM. Lens depression and aqueous outflow in enucleated primate eyes. Am f Ophthalmol 1973; 76:632-40.

8 Gimbel HV, Brown D, Fine H. Advanced phacoemulsification technique. In: Gills JP, ed. Cataract surgery. The state of the art. Thorofare, NJ : Slack Inc, 1998:101-23.

9 Kaufman PL, Wiedman T, Robinson JR. Cholinergics. In: Sears ML, ed. Handbook of experimental pharmacology. VolSears ML, ed. Handbook of experimental pharmacolog.

ume 69. New York: Springer-Verlag, 1984:149-91.
Galin MA, Baras I, Perry R. Intraocular pressure following cataract extraction. Arch Ophthalmol 1961;66:80-5.

11 Radius RL, Schultz K, Sobocinski K, et al. Pseudophakia and intraocular pressure. Am f Ophthalmol 1984;97:73842

12 Suzuki R, Tanaka K, Sagara T, et al. Reduction of intraocular pressure after phacoemulsification and aspiration with intraocular lens implantation. Ophthalmologica 1994;208: 254-8.

13 Jahn CE. Reduced intraocular pressure after phacoemulsification and posterior chamber intraocular lens implantacation and posterior chamber intraocular le
tion. f Cataract Refract Surg 1997;23:1260-4.

14 Lee PF, Trotter RR. Tonographic and gonioscopic studies before and after cataract extraction. Arch Ophthalmol 1957; 58:407-16.

15 Meyer MA, Savitt ML, Kopitas E. The effect of phacoemulsification on aqueous outflow facility. Ophthalmology 1997; 104:1221-7.

16 Tennen DG, Masket S. Short- and long-term effect of clear corneal incisions on intraocular pressure. $\mathcal{F}$ Cataract Refract Surg 1996;22:568-70.

17 Arciniegas A, Amaya LE, Vicioso G. Mechanical behavior of the ciliary-lens-zonule-ciliary body system. Ophthalmologica 1980;181:114-7.

18 Croft MA, Glasser A, Heatley, GA, et al. The relationship between ciliary muscle function and the lens. Invest Ophthalmol Vis Sci 1998;39:S312. 